\title{
Eutrofização e mudanças no regime hidrológico: um risco na bacia do Rio Urupá, Amazônia brasileira
}

O uso e ocupação do solo em uma bacia hidrográfica reflete diretamente na qualidade da água de seus rios. Assim, considerando o expressivo desenvolvimento de atividades agropecuárias, agroindustriais, minerárias, piscícolas e as inerentes a zona urbana na bacia hidrográfica do rio Urupá nos últimos anos, objetivou-se avaliar a potencial eutrofização do rio Urupá, sob a influência do uso e ocupação e do regime hidrológico da bacia considerando mudanças observadas no sudoeste da Amazônia Brasileira. Para tanto, determinou-se a concentração de Clorofila a e Fósforo Total presentes na zona superficial do rio, em 10 pontos amostrais ao longo de seu eixo longitudinal, com periodicidade bimestral, no período de maio/2018 a abril/2019, com avaliação da influência da precipitação pluviométrica no período. O índice de estado trófico pelo parâmetro de clorofila a (IETChl a) apresentou características de baixa produtividade, enquanto o índice de estado trófico pelo parâmetro de fósforo total (IETPT), do P2 ao P10 apontou potencial à eutrofização, em níveis intermediários. Para tanto, a disponibilidade de fósforo total (PT) na coluna líquida aliada as mudanças no regime de precipitação pluviométrica no sudoeste da Amazônia, põe em risco a qualidade da água da bacia e acendem uma alerta a adoção de medidas à manutenção.

\section{Eutrophization and changes in hydrological regime: a risk in the Urupá River basin, Brazilian Amazon}

\begin{abstract}
The use and occupation of land in a hydrographic basin directly reflects the quality of the water in its rivers. Thus, considering the expressive development of agricultural, agro-industrial, mining, fish farming activities and those inherent to the urban area in the hydrographic basin of the Urupá River in recent years, the objective was to evaluate the potential eutrophication of the Urupá River, under the influence of use and occupation and the hydrological regime of the basin considering changes observed in the southwest of the Brazilian Amazon. For this purpose, the concentration of Chlorophyll a and Total Phosphorus present in the superficial zone of the river was determined in 10 sample points along its longitudinal axis, with bimonthly periodicity, from May/2018 to April/2019, with evaluation of the influence rainfall in the period. The trophic status index by the chlorophyll a parameter (IETChl a) showed low productivity characteristics, while the trophic status index by the total phosphorus parameter (IETPT), from P2 to P10, pointed to the potential for eutrophication, at intermediate levels. To this end, the availability of total phosphorus (PT) in the liquid column combined with changes in the rainfall regime in southwestern Amazonia, puts the water quality of the basin at risk and ignites an alert for the adoption of maintenance measures.
\end{abstract}

Keywords: Trophic state index; Antrhropic eutrophication; Rainfall.

Topic: Desenvolvimento, Sustentabilidade e Meio Ambiente

Reviewed anonymously in the process of blind peer.
Received: 04/12/2020

Approved: 21/12/2020
Edilene da Silva Pereira (ii)

Instituto Federal de Rondônia, Brasil

http://lattes.cnpq.br/7561916615362202

http://orcid.org/0000-0002-3441-3116

edilene.pereira@ifro.edu.br

Ranieli dos Anjos de Souza

Instituto Federal de Rondônia, Brasil

http://lattes.cnpq.br/2492735010487145

http://orcid.org/0000-0003-1408-4826

ranieli.anjos@ifro.edu.br

Nairo Rafael da Silva

Universidade Federal de Rondônia, Brasil

http://lattes.cnpq.br/6441980310135850

nairors@hotmail.com

\begin{abstract}
Alberto Dresch Webler ii
Universidade Federal de Rondônia, Brasil http://lattes.cnpq.br/2636465000898348 http://orcid.org/0000-0001-5777-2982

alberto.webler@unir.br

Fernanda Bay Hurtado (ic

Universidade Federal de Rondônia, Brasil http://lattes.cnpq.br/9700422467259382 http://orcid.org/0000-0001-7593-1852 fernandabay@unir.br
\end{abstract}

Referencing this:

PEREIRA, E. S.; SOUZA, R. A.; SILVA, N. R.; WEBLER, A. D.; HURTADO, F. B.. Eutrofização e mudanças no regime hidrológico: um risco na bacia do Rio Urupá, Amazônia brasileira. Revista Ibero Americana de Ciências Ambientais, v.11, n.7, p.557-568, 2020. DOI: http://doi.org/10.6008/CBPC2179-6858.2020.007.0043 


\section{INTRODUÇÃO}

Quando as atividades econômicas não são planejadas de acordo com a capacidade de suporte ambiental de uma bacia hidrográfica, a pressão das modificações que essas ocasionam sobre o meio podem resultar em severos prejuízos ambientais, sociais e econômicos (MEZZOMO et al., 2016). A redução da diversidade de hábitats e depleção da biodiversidade pelo desmatamento desordenado e a contaminação do solo, são exemplos dos problemas associados a gestão inadequada da bacia, que por sua vez refletem diretamente na modificação das características limnológicas das águas de seus rios (MOURA et al., 2010).

Essas alterações podem resultar na eutrofização e contaminação dos corpos hídricos pela lixiviação da matéria orgânica, nutrientes e minerais provenientes do solo desflorestado, aumento da morbidade humana em decorrência de doenças de veiculação hídrica pelo lançamento de resíduos sólidos e efluentes no meio, elevação nos custos de tratamento da água, etc. (BRIZZI et al., 2019; STAGER et al., 2018).

A eutrofização antrópica consiste na proliferação excessiva da comunidade fitoplanctônica, algas e cianobactérias, que podem produzir toxinas altamente potentes, conhecidas como cianotoxinas, de efeitos neurotóxicos, hepatotóxicos ou dermatotóxicos (CYRINO et al., 2010). Podem acarretar ainda, efeitos indesejáveis como a hipóxia (SINHA et al., 2017) maus odores, mortandade de peixes, mudanças na biodiversidade aquática e contaminação das águas destinadas ao abastecimento público (CETESB, 2011).

A fim de classificar os corpos d'água em diferentes graus de qualidade quanto ao enriquecimento por nutrientes e seu efeito relacionado ao crescimento excessivo de fitoplânctons, o Índice do Estado Trófico (IET) se apresenta como uma importante ferramenta de avaliação (LAMPARELLI, 2004).

Os valores do IET podem ser calculados a partir dos valores de fósforo, entendidos como uma medida do potencial risco de eutrofização, eis que esse elemento age como nutriente atuando como agente causador do processo (LAMPARELLI, 2004; CETESB, 2011; ANA, 2019), e é considerado o principal responsável pela eutrofização de sistemas de água doce (SINHA et al., 2017).

A Clorofila a ( $\mathrm{Chl}$ a) é um parâmetro importante na indicação do estado trófico de ambientes aquáticos, útil na avaliação de impacto de contaminantes orgânicos e inorgânicos e outros distúrbios, eis que a Chl à é encontrada em todos os grupos de algas e cianobactérias, que tem a sua biomassa como indicador do enriquecimento por nutrientes, principalmente nitrogênio e fósforo (CETESB, 2011).

Além disso, estudos apontam que o clima apresenta relação direta com a eutrofização, e é, portanto, uma variável a ser considerada na gestão dos recursos hídricos, no planejamento e ordenamento das atividades de acordo com as características do solo, geologia, vegetação, disponibilidade hídrica, etc. (SINHA et al., 2017; POMATI et al., 2016).

Nesse contexto, o rio Urupá, especificamente de onde provém o abastecimento público de água potável do município de Ji-Paraná/RO, devido ao expressivo crescimento de algumas atividades nos últimos anos, têm como consequência a produção de resíduos que, em grande maioria, o lançamento dos efluentes são nos corpos hídricos da bacia, o que supostamente pode promover a sua eutrofização artificial. Assim, objetivou-se avaliar a potencial eutrofização do rio Urupá, bem como relacionar os riscos inerentes ao regime 
hidrológico de sua bacia.

\section{METODOLOGIA}

\section{Área de Estudo}

A bacia hidrográfica do rio Urupá localiza-se na porção centro-leste do estado de Rondônia, com sua nascente na Reserva Indígena Uru-Eu-Wau-Wau/Parque Nacional do Pacaás Novos e desembocadura no rio Ji-Paraná. Com área de drenagem de $4.209 \mathrm{Km}^{2}$, compreende nove municípios, de São Miguel do Guaporé, Mirante da Serra, Jaru, Urupá, Alvorada do Oeste, Nova União, Ji-Paraná, Nova União, Ouro Preto do Oeste, Presidente Médici e Ji-Paraná, da nascente em direção a foz.

\section{Coletas e Análises}

O principal curso d'água da bacia é o rio Urupá, de $270,533 \mathrm{~km}$ de comprimento, o qual constitui o objeto de estudo em questão (Figura 1).
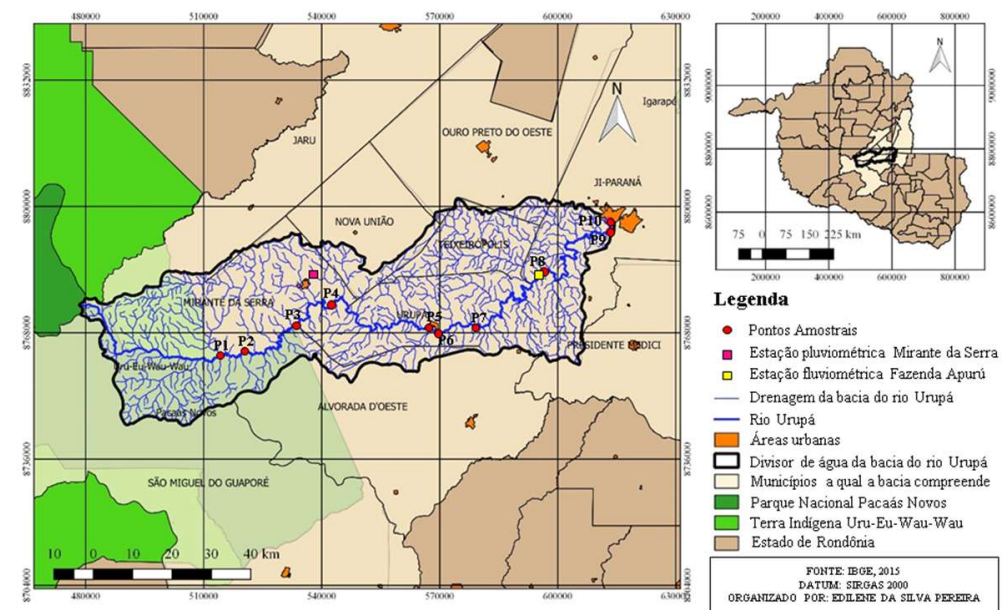

Figura 1: Mapa de localização da Bacia do rio Urupá e os pontos amostrais

Para a avaliação da qualidade da água, realizou-se seis coletas bimestrais, no período de maio/2018 a abril/2019, em 10 pontos amostrais ao longo do rio Urupá, em pontos denominados de P1 a P10, de forma sucessiva da nascente ao exutório, em áreas de drenagem que representasse os principais usos e ocupação do solo na bacia. A coleta no P1, por se tratar de local dentro do Parque Nacional (PARNA) do Pacaás Novos sobreposto pela Terra Indígena (TI) Uru-Eu-Wau-Wau, precedeu de autorização do SISBIO ${ }^{1}$.

Para as amostragens, no P1 as coletas se deram a pé ou barco, no P2, P5, P7 e P10 pela margem do rio com auxílio de estrutura de alumínio, e no P3, P4, P6, P8 e P9 de cima de pontes. Em todos os pontos, buscou-se considerar o centro da seção transversal como local de coleta, à $30 \mathrm{~cm}$ de profundidade (CETESB, 2011). Algumas análises foram realizadas in loco, as demais, procedeu-se o armazenamento das amostras em recipientes adequados, devidamente identificados, com acondicionamento em caixas de isopor contendo gelo, e transporte até o laboratório de saneamento (SANEAM), da Universidade Federal de Rondônia (UNIR),

\footnotetext{
${ }^{1}$ SISBIO - sistema de atendimento à distância para autorizações para a realização de pesquisa em unidades de conservação federais, do Instituto Chico Mendes (ICMBio). Autorização no 66986-1, de 11/02/2019. Código de autenticação: 0669860120190211.
} 
Campus Ji-Paraná, onde realizou-se a maioria das análises.

\section{Análises Físico-Químicas}

Em laboratório, seguindo o Standard Methods for the Examination of Water and Wastewater (SMEWW), determinou-se a Chl à pelo método espectrofotométrico $10200 \mathrm{H}$. (APHA et al., 1999), via equipamento Vis Spectrophotometer V - M5, com extração do pigmento com etanol a quente (CETESB, 2014).

A determinação do fósforo total (PT) se deu pela redução com ácido ascórbico, método P.E. 4500 do SMWW, adaptado de Golterman et al. (1969), com curvas de calibração (5 a $100 \mu \mathrm{g} . \mathrm{L}^{-1}$ ) e leitura no espectrofotômetro visível, a 882 nm de absorbância (APHA et al., 1999).

\section{Determinação do Índice de Estado Trófico (IET)}

Calculou-se o Índice de Estado Trófico (IET) de duas formas, pelas concentrações de Chl a e fósforo total, vide as Equações 1 e 2 (SCHNEIDER et al., 2016).

$$
\begin{gathered}
\mathrm{IET}_{(\mathrm{Chl} \text { a) }}=10 \cdot\left\{6-\left[\frac{0,7-0,6 \cdot \ln (\mathrm{Chl} a)}{\ln (2)}\right]\right\}-20 \\
\mathrm{IET}_{(\mathrm{PT})}=10 \cdot\left\{6-\left[\frac{0,42-0,36 \cdot \ln (\mathrm{PT})}{\ln (2)}\right]\right\}-20
\end{gathered}
$$

Em que:

IET (chla) - índice de estado trófico referente a clorofila $a$; IET (PT) - índice de estado trófico referente ao fósforo total; Chl a e PT admitem a unidade de medida $\mu \mathrm{g} \cdot \mathrm{L}^{-1}$, referente a concentração na superfície da água; Embora seja usual calcular a média do $\mathrm{IET}_{\mathrm{Chl}}$ a $\mathrm{com}_{\mathrm{O}} \mathrm{IET}_{\mathrm{PT}}$, optou-se por não proceder dessa forma, por entender que os dados referentes ao período chuvoso seriam mascarados, tendo em vista a ausência de Clorofila nesse período. Portanto, os dois índices foram apenas comparados.

Constitui a classificação do IET seis graus de trofia (Tabela 1), associadas a qualidade dos corpos hídricos, que variam de características como limpos até corpos d'água afetados significativamente pelas elevadas concentrações de matéria orgânica e nutrientes, com comprometimento acentuado nos seus usos, com episódios de florações de algas ou mortandades de peixes (LAMPARELLI, 2004).

Tabela 1: Classificação do Índice de Estado Trófico (IET).

\begin{tabular}{|l|l|l|}
\hline Valor do IET & Classes de estado trófico & Cores das Classes \\
\hline $\mathrm{IET} \leq 47$ & Ultraoligotrófico & Azul \\
\hline $47<\mathrm{IET} \leq 52$ & Oligotrófico & Verde \\
\hline $52<\mathrm{IET} \leq 59$ & Mesotrófico & Amarelo \\
\hline $59<\mathrm{IET} \leq 63$ & Eutrófico & Marrom \\
\hline $63<\mathrm{IET} \leq 67$ & Supereutrófico & Vermelho \\
\hline $\mathrm{IET}>67$ & Hipereutrófico & Roxo \\
\hline
\end{tabular}

Fonte: adaptado de Lamparelli (2004).

\section{Dados da Ocupação da Bacia do Rio Urupá e Confecção de Mapas}

Os dados sobre as atividades econômicas em desenvolvimento na bacia até março/2018, passiveis de licenciamento, foram levantados junto as Secretaria de Estado do Desenvolvimento Ambiental de Rondônia (SEDAM), Secretaria Municipal de Meio Ambiente (SEMMA) de Urupá e Secretaria Municipal de 
Meio Ambiente (SEMEIA) de Ji-Paraná.

As informações referentes ao uso e ocupação da bacia do rio Urupá foram geradas por meio das imagens Sentinel 2A datadas de julho de 2018, obtidas gratuitamente na plataforma do United States Geological Survey (USGS), e processadas no Sistema de Informação geográfica (SIG) $\operatorname{ArcMap}^{\circledR}{ }^{2}$. Foram utilizados os tiles 20LMN, 20LNN, 20LPN e 20LNP. Neste mesmo SIG gerou-se os mapas de solos, com a base do Instituto Brasileiro de Geografia e Estatística (IBGE, 2003), e os mapas de IET.

\section{Informações sobre o Regime Hidrológico da Bacia do Rio Urupá}

Levantamento de dados de precipitação pluviométrica e vazão junto no ao Sistema de Informações Hidrológicas da Agência Nacional de Águas (ANA), portal "Hidroweb" versão web 3.0 @ 2018, na estação pluviométrica Mirante da Serra (código 01062003) e estação fluviométrica Fazenda Apurú (código 15558500), operadas pela Companhia de Pesquisas de Recursos Minerais (CPRM) (ANA, 2019).

Utilizou-se ainda do estudo da arte para a caracterização acerca das alterações no regime hidrológico na bacia amazônica, referente ao sudoeste da bacia.

\section{RESULTADOS}

A precipitação pluviométrica de maio a outubro/2018 foi de $237,9 \mathrm{~mm} / \mathrm{seca}$ e enquanto de novembro/2018 a abril/2019 foi de 1.480,90 mm/período de chuvas, com total de 1.718,8 mm/ano (ANA, 2020; FISCH et al., 2019). Em fevereiro/2019, ocorreu o maior volume acumulado de chuvas, com 380,8 mm, e o menor em julho/2018, com 00 mm sem registro de ocorrência. No rio Urupá as descargas hídricas apresentaram vazões (Q) mínima e máxima de $12,33 \mathrm{~m}^{3} \cdot \mathrm{s}^{-1}$ e $517,92 \mathrm{~m}^{3} \cdot \mathrm{s}^{-1}$, em novembro/2018 e março/2019, respectivamente (ANA, 2019)

A média de Clorofila $a$ na estação seca foi de 3,58 $\mu \mathrm{g} \cdot \mathrm{L}^{-1}$, desvio padrão de $\pm 4,01$ e com valor máximo

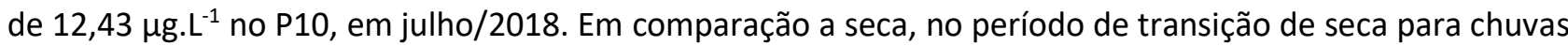
(outubro/2018), a média desse parâmetro foi superior a duas vezes, com 7,95 $\mu \mathrm{g}$.L-1, desvio padrão de $\pm 3,46$,

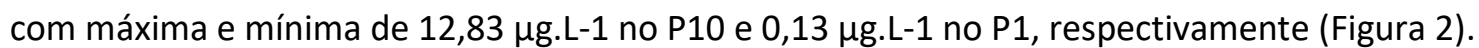

Os valores de Chl a se enquadraram no padrão de referência da Resolução CONAMA n $357 / 2005$, Art. 15, Inciso VII, que admite valor máximo de $30 \mu \mathrm{g} \cdot \mathrm{L}^{-1}$. No período chuvoso, não se constatou concentração do pigmento na zona superficial do rio. Ao analisar as concentrações de fósforo por amostragem referente às coletas de 14/10/2018 e 24/11/2018, (Tabela 2), no P5, P6 e P7 (seca) e P5, P6, P7, P8, P9 e P10 (chuvas), os valores excederam o padrão de referência de $100 \mu \mathrm{g} \cdot \mathrm{L}^{-1}$ da CONAMA n 357/2005 (CONAMA, 2005).

Tabela 2: Resultados das análises de Fósforo Total $\left(\mu \mathrm{g} . \mathrm{L}^{-1} \mathrm{P}\right)$ no eixo longitudinal do rio.

\begin{tabular}{|c|c|c|c|c|c|c|c|c|}
\hline \multirow[t]{2}{*}{ Pts. } & \multicolumn{3}{|c|}{ 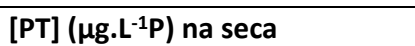 } & \multirow[t]{2}{*}{ DP seca } & \multicolumn{3}{|c|}{ [PT] ( $\left.\mu \mathrm{g} \cdot \mathrm{L}^{-1} \mathrm{P}\right)$ nas chuvas } & \multirow[t]{2}{*}{ DP chuvas } \\
\hline & C1 & C2 & C3 & & C4 & C5 & C6 & \\
\hline P1 & 1,71 & 11,71 & 48,14 & \pm 24.44 & 33,24 & 9,04 & 17,17 & \pm 12.32 \\
\hline $\mathrm{P} 2$ & 30,29 & 9,57 & 45,29 & \pm 17.93 & 45,08 & 16,66 & 18,53 & \pm 15.90 \\
\hline P3 & 28,38 & 9,57 & 76,00 & \pm 34.24 & 65,28 & 20,47 & 28,72 & \pm 23.85 \\
\hline
\end{tabular}

${ }^{2}$ ArqMap licenciado para Instituto Federal Educação, Ciência e Tecnologia de Rondônia, vide código EFL497592321. 


\begin{tabular}{|l|l|l|l|l|l|l|l|l|}
\hline P4 & 38,86 & 11,00 & 98,86 & \pm 44.90 & 79,21 & 26,57 & 42,98 & \pm 26.94 \\
\hline P5 & 67,43 & 9,57 & $104,57^{*}$ & \pm 47.87 & $118,21^{*}$ & 38,01 & 52,48 & \pm 42.75 \\
\hline P6 & 66,00 & 14,57 & $106,00^{*}$ & \pm 45.83 & $107,07^{*}$ & 44,87 & 59,95 & \pm 32.45 \\
\hline P7 & 59,81 & 12,43 & $133,14^{*}$ & \pm 60.82 & $100,80^{*}$ & 41,05 & 57,23 & \pm 30.90 \\
\hline P8 & 85,05 & 32,43 & 67,43 & \pm 26.78 & $125,18^{*}$ & 46,39 & 64,70 & \pm 41.23 \\
\hline P9 & 93,62 & 9,57 & 46,71 & \pm 42.12 & $127,27^{*}$ & 50,96 & 66,06 & \pm 40.41 \\
\hline P10 & 93,14 & 10,29 & 51,71 & \pm 41.43 & $120,99^{*}$ & 54,01 & 59,95 & \pm 37.08 \\
\hline
\end{tabular}

P1 a P10 - pontos amostrais no perfil longitudinal do rio; Período seco - maio a outubro; Período chuvoso - novembro a abril. C1 - coleta em 22/05/2018; C2 - coleta em 31/07/2018; C3 - coleta em 14/10/2018; C4 - coleta em 24/11/2018; C5 - coleta em 26/01/2019; C6 - coleta em 04/04/2019; DP - desvio padrão; $\left({ }^{*}\right)$ Concentrações acima do padrão de $100 \mu \mathrm{g} . \mathrm{L}^{-1} \mathrm{PT}$ da Resolução CONAMA n 357/2005 (CONAMA, 2005).

Para tanto, ao se considerar as concentrações médias de PT por período (Figura 3), a transição secachuvas foi o mais crítico entre os períodos para o parâmetro, por exceder os valores de referências da Resolução CONAMA n 357/2005 (BRASIL, 2005) nos P5, P6 e P7.

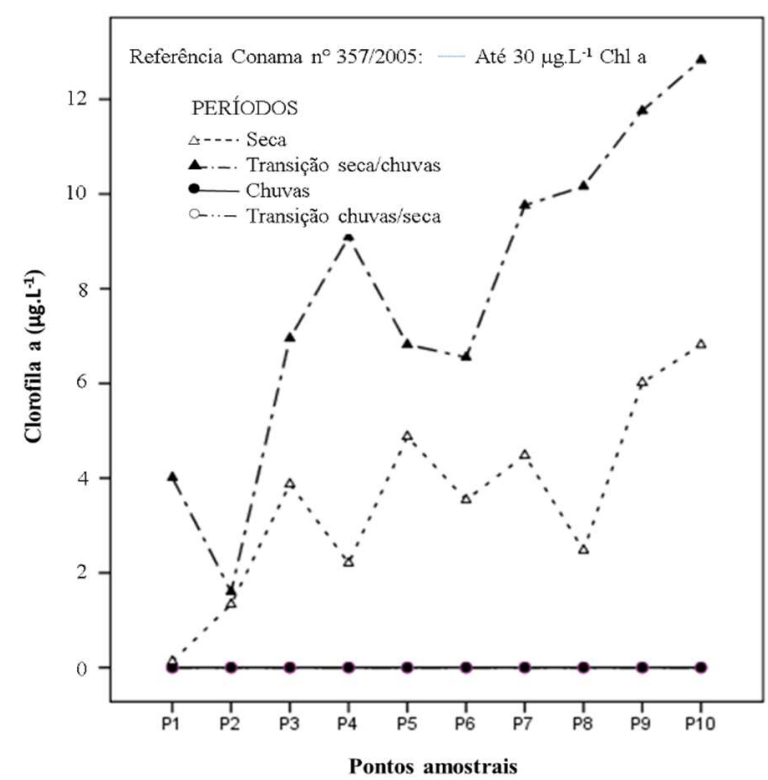

Figura 2: Comparação dos valores médios de Clorofila a no rio Urupá, quanto a variabilidade espacial, sazonal e o valor de referência estabelecido na Resolução Conama $n^{\circ} 357 / 2005$.

Chl a: clorofila a; Seca: maio a setembro de 2018;

Transição seca/chuvas: outubro/2018; Chuvas: novembro/2018 a março/2019; Transição chuvas/seca: abril.

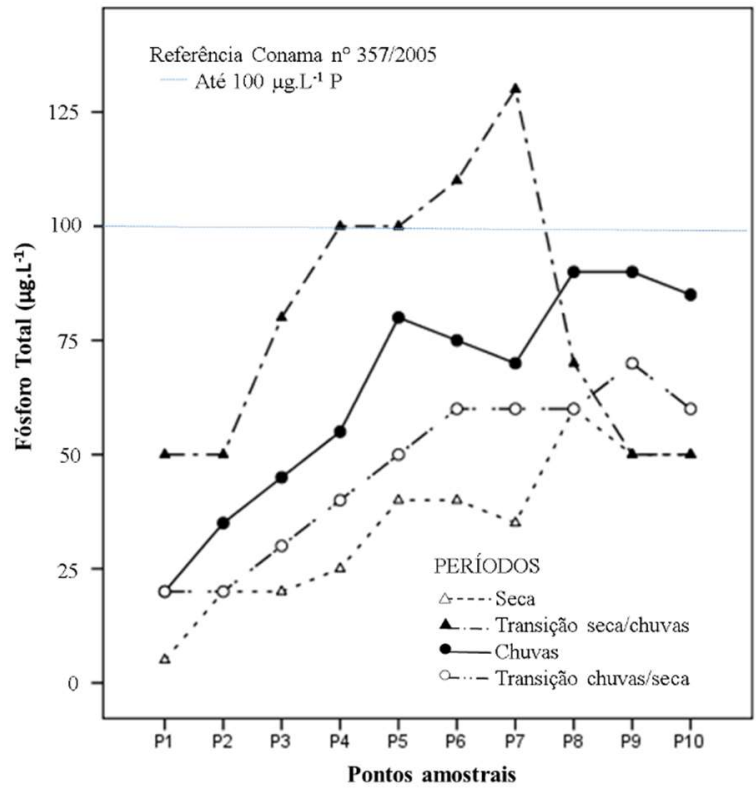

Figura 3: Comparação dos valores médios de Fósforo Total no rio Urupá, quanto a variabilidade espacial, sazonal e o valor de referência estabelecido na Resolução Conama $n^{\circ}$ 357/2005.

P: fósforo; Seca: maio a setembro de 2018; Transição seca/chuvas: outubro/2018; Chuvas: novembro/2018 a março/2019; Transição chuvas/seca: abril.

\section{DISCUSSÃO}

Com as reduzidas concentrações de $\mathrm{Chl}$ a, o IET $\mathrm{Chl}$ a apresentou classe ultraoligotrófica em todos os pontos amostrais na seca, chuvas e transição chuvas/seca (Figura 4).

Entretanto, o IET $\mathrm{Chl}$ a apresenta limitações, uma vez que a produção de $\mathrm{Chl}$ a depende de algumas variáveis além da carga nutricional. Segundo Marreto et al. (2017), as variáveis ligadas a produção primária são compostas pelos nutrientes de forma geral, com destaque ao Fósforo, e clorofila $a$, que podem sofrer influência dos aspectos ambientais como o regime hidrológico, padrões dos ventos, e pelas diferenças entre os locais quanto a origem e intensidade de insumo.

Ocorreu que, no período de transição seca/chuvas, embora houve ocorrência de chuvas, a vazão do 
rio encontrava-se reduzida, e por sua vez a turbulência no regime de escoamento, o que, ligado a elevada incidência solar e disponibilidade de nutrientes na coluna líquida, propiciou condições a produção primária.

No caso do rio Urupá, mesmo no período de estiagem, o regime de escoamento apresenta-se acima do requerido por esses organismos. Maranho et al. (2017) alertam ainda para a presença de possíveis contaminantes, capazes de inibir o crescimento algáceo e mascarar os resultados.
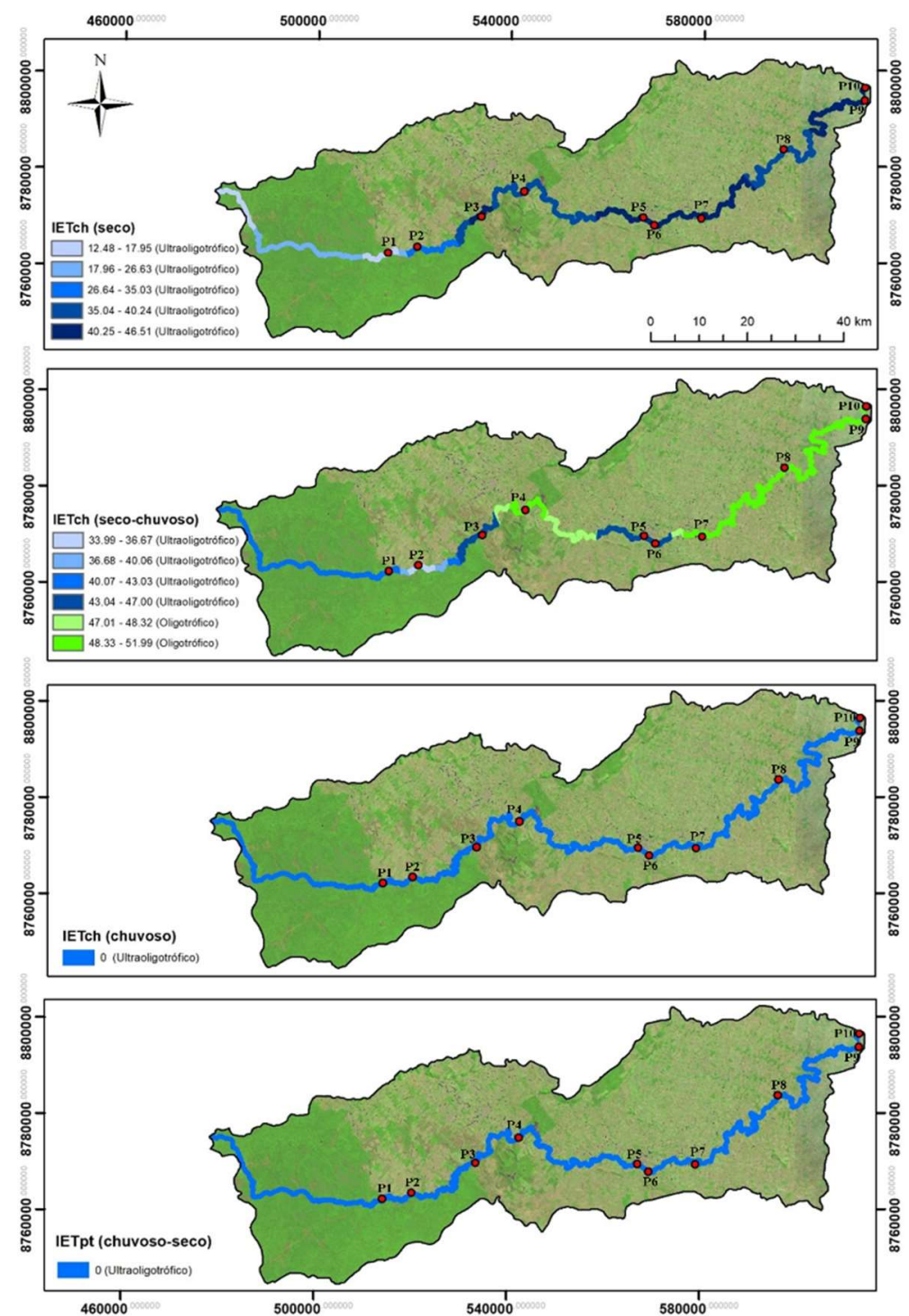

Figura 4: Índice de Estado Trófico (IET) pelo parâmetro de Clorofila a no perfil longitudinal do rio.

a) seca: maio e julho/2018; b) transição seca/chuvas: outubro/2018. c) chuvas: novembro/2018 e janeiro/2019; d) transição chuvas/seca: abril/2019.

No período de transição seca/chuvas houve alteração do enquadramento da classe de $C_{h l} a$ ultraoligotrófica em $50 \%$ dos pontos na bacia para a classe oligotrófica, no P4, P7, P8, P9 e P10 (Figura 4). Isso indica que a produção no corpo hídrico é insignificante em praticamente todo o período (LAMPARELLI, 2004), e não acarreta prejuízos aos usos da água para os diversos fins aos quais se destina na bacia.

Para tanto, a maior concentração de fósforo total ocorreu também no período de transição seca/chuvas (outubro) (Figura 3), o que denota característica peculiar ao período, e, portanto, necessidade de maior atenção as fontes de poluição, tendo em vista o aumento de incremento nutricional no corpo hídrico e a possibilidade de eutrofização referente. 
No período de transição seca/chuvas a concentração média de fósforo teve um aumento de 112 \% em relação a seca, com 77,79 $\mu \mathrm{g} \cdot \mathrm{L}^{-1}$, com destaque ao P7 que apresentou a maior concentração, com 133,14 $\mu \mathrm{g} . \mathrm{L}^{-1}$. O valor mínimo neste período foi de $45,29 \mu \mathrm{g} \cdot \mathrm{L}^{-1}$, e ao compará-lo com o mínimo observado na seca, o incremento supera $2648 \%$, para igual desvio padrão.

O destaque das concentrações de PT nesse período é porque em outubro houve o registro de ocorrência das primeiras chuvas da temporada, promovendo o carreamento parcial de poluentes disponíveis no solo para o leito do rio.

As concentrações de PT na coleta de 24/11/2018 chamaram atenção por apresentar valores excedentes ao padrão de referência em mais de 60 \% dos pontos amostrais. Uma vez que em novembro inicia o período chuvoso no sudoeste da Amazônia (FISCH et al., 2019), com elevados volumes de precipitação, os poluentes oriundos das atividades antrópicas do uso e ocupação do solo na bacia são carreados para os corpos hídricos, causando a alteração de sua qualidade, o que também foi constatado por Farage et al. (2010) no rio Pomba, na zona da mata mineira, para as concentrações de PT de 0,08 e 0,11 mg $\mathrm{L}^{-1}$.

Os principais intervenientes relacionados a presença de fósforo total são os dejetos animais gerados na atividade agropecuária, adubação da terra, bem como os resíduos sólidos e águas residuárias com disposição no solo e erosão (STAGER et al., 2018).

$\mathrm{Na}$ campanha de coletas seguinte, em janeiro/2019, as concentrações de fósforo obtidas foram compatíveis com o padrão de referência, o que ocorreu devido ao aumento da vazão nos corpos hídricos o que causou consecutiva diluição dos poluentes ali presentes, e por que grande parte desses nutrientes já haviam sido carreados para o corpo hídrico.

Em estudo elaborado na bacia do Ribeirão Vermelho, em Minas Gerais, alguns autores observaram que no período chuvoso, a vazão de um rio tende a apresentar maiores volumes, com reflexos na qualidade das águas de duas formas: com efeito de diluição pelo aumento da vazão, e com inserção de poluentes pela lixiviação e carreamento do solo. Em estudos no rio Caiabi, no Mato Grosso, Schneider et al. (2016), também constataram no período de chuvas, a tendência de valores mais elevados de alguns poluentes como o nitrogênio (SINHA et al. 2017), o que associaram a ação do escoamento superficial das áreas agrícolas e de pastagens pela ocorrência de eventos de precipitação, em contraste com a estação seca. Revelaram ainda que o local de maior concentração de PT localiza-se a jusante da zona urbana de uma cidade e um sistema intensivo de produção animal.

As alterações de PT do P5 ao P10 na bacia do rio Urupá (Tabela 2), podem ser associadas aos principais usos e ocupação do solo referentes as atividades agropecuárias, mineração, agroindústrias, pisciculturas desenvolvidas nos municípios de Alvorada do Oeste, Ji-Paraná, Nova União, Ouro Preto do Oeste, Presidente Médici e Urupá, além daquelas inerentes a zona urbana de Urupá.

Embora no período inicial das chuvas as concentrações de PT ascenderam os valores de referência, com o aumento das precipitações pluviométricas, houve a redução das concentrações por meio da diluição dos poluentes no leito do rio (Figura 3). 
Assim, as atividades que podem contribuir para o aporte de nutrientes no corpo hídrico na seca, são aquelas de natureza de poluição pontual, cujos despejos ocorrem diretamente nos corpos hídricos da bacia, como mineração, agroindústria, piscicultura e as cidades, com lançamentos de águas residuárias e outros resíduos. Para tanto, as atividades de maior impacto no período das chuvas, são aquelas cuja poluição apresentam natureza difusa, que através das chuvas, promove o escoamento superficial, o carreamento e lixiviação dos poluentes presentes no solo paro o rio, como proveniente das atividades agropecuárias e inerentes as cidades. Além disso, o tipo de solo predominante na região, o argissolo vermelho-amarelo por se tratar de um solo vulnerável a erosão (EMBRAPA, 2018; EMBRAPA, 2019; IBGE, 2003), propicia a inserção de sedimentos na bacia.

Um alerta a esse respeito, é que o P9 se localiza a montante da captação de água para tratamento e distribuição pública do município de Ji-Paraná, dista a 3,5 km, o que em caso de estiagens mais severas, com a redução da vazão do rio, pode-se constar concentrações mais elevadas de PT e outros nutrientes, ocasionando problemas de eutrofização por floração de algas e depleção da qualidade dessa da água.
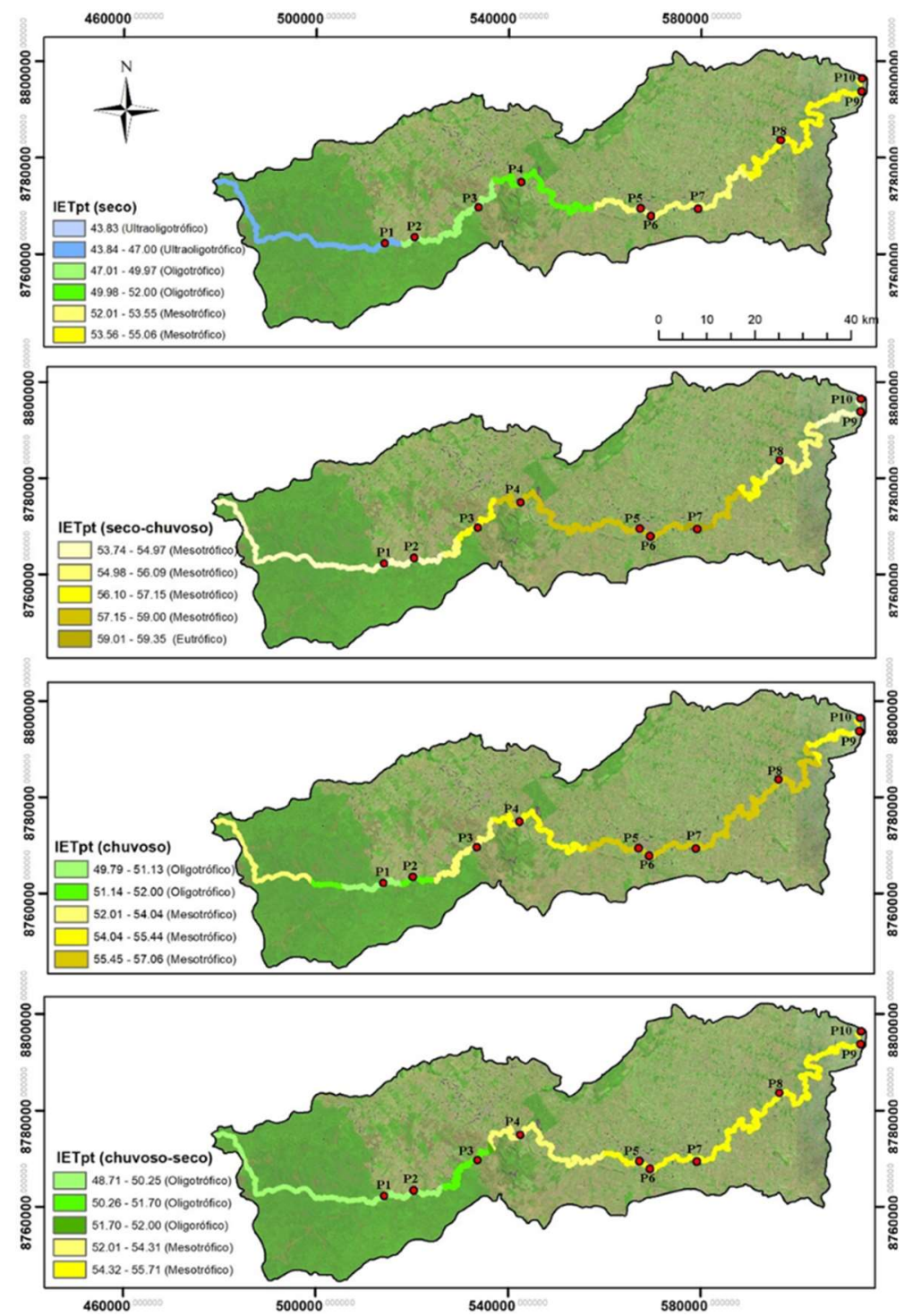

Figura 51: Índice de Estado Trófico (IET) pelo parâmetro de Fósforo Total (IETPT), no perfil longitudinal da bacia. a) seca: maio/2018 e julho/2018; b) transição seca/chuvas: outubro/2018. c) chuvas: novembro/2018 e janeiro/2019; d) transição chuvas/seca: abril/2019. 
Assim, considerando valores médios da estação seca, transição seca, transição seca/chuvas, chuvas e transição chuvas/seca, os resultados de IET PT demostraram que o rio Urupá dispõe de concentração intermediária de PT, com enquadramento dominante na classe Mesotrófica (Figura 5), o que o torna vulnerável a possíveis implicações de qualidade das águas (LAMPARELLI, 2004).

Nota-se, é a partir do P2 que o uso e ocupação do solo na bacia se acentua, o que corrobora com alteração da qualidade da água em decorrência das atividades ora desenvolvidas (SCHNEIDER et al., 2016; OLIVEIRA et al., 2017).

Um fator relevante na gestão das atividades da bacia e a mitigação das fontes de eutrofização antrópica é que, mesmo ao cessar as fontes de nutriente causal, os efeitos da eutrofização poderão persistir por séculos, ou ainda se tornar irreversível pelo desequilíbrio termodinâmico instaurado, ou seja, é mais fácil prevenir do que revertê-la (STAGER et al. 2018).

Outra fonte de preocupação são as alterações no regime de precipitação na bacia Amazônica, que vem ocorrendo desde 1981, culminando na redução no total da precipitação no sul da Amazônia, contraposto com o aumento pluviométrico no norte da bacia (ESPINOZA et al., 2018).

A estação seca aumentou cerca de um mês no sul da Amazônia, além disso alguns cenários climáticos sugerem um aumento na frequência de dias secos, com precipitações inferiores a $1 \mathrm{~mm} / \mathrm{dia}$, e duração da estação seca na Amazônia, com intensificação de eventos hidrológicos extremos, como secas prolongadas ou enchentes (ESPINOZA et al., 2018).

Existem duas vertentes que se complementam na explicação dessas alterações, sendo uma relacionada as variações da temperatura da superfície dos oceanos Atlântico (El Niño) e Pacífico, intensificadas pelo avanço do desmatamento em larga escala e mudanças no uso da terra para agropecuária nas últimas décadas na região Amazônica (NOBRE, 2019; ESPINOZA et al., 2018; KANNA et al., 2017). Estudo realizado por Kanna et al. (2017) sobre alterações climáticas no Estado de Rondônia, ratificam as mudanças no hidroclima em decorrência de três décadas de desmatamento no Estado, salientando que a floresta atua como um regulador climático e uma fonte de umidade para precipitação através da reciclagem de umidade (ESPINOZA et al., 2018; BRIZZI et al., 2019).

Para tanto, estudos de modelagem experimental e observacionais apontam que o desmatamento afeta a energia e o balanço hídrico na bacia Amazônica (DAVIDSON et al., 2012). Assim, na perspectiva de melhor compreender sobre as mudanças climáticas, há a necessidade de uma abrangente descrição e análise de mudanças na cobertura vegetal e o uso da terra na Amazônia, para identificar claramente mecanismos pelos quais eles poderiam afetar a ocorrência de dias secos e úmidos e o início e fim do período úmido e estações secas (ESPINOZA et al., 2018).

Estudos realizados no nordeste dos Estados Unidos, em região conhecida como cinturão do milho, reforçam a preocupação sobre a mudança no regime de precipitação e a eutrofização, com a ocorrência de problemas relacionados na Índia, na China e no Sudeste Asiático e enfatizam a necessidade de estratégias de gestão da qualidade da água, visto que o crescimento populacional e as mudanças nas práticas de manejo da terra impulsionarão os impactos pela eutrofização (SINHA et al., 2019). E chamam atenção para os risco de 
regiões de elevada produção agricola e emprego de fetilizantes.

Dessa forma, pelo IET $\mathrm{Chl}$ a o rio Urupá não apresenta risco potencial de eutrofização, independente da estação do ano. Por outro lado, pela disponibilidade nutricional no corpo hídrico, verificado pelo IETPT, e pela possibilidade de uma mudança no regime hidrológico da bacia do rio Urupá, há o risco de eutrofização, principalmente se houver uma seca prolongada intercalada de eventos de precipitação característico de transição.

\section{CONCLUSÕES}

O IET Chl a não se constitui uma ferramenta estável para avaliação da potencial eutrofização do rio Urupá, tendo em vista que o regime de escoamento do rio pode estar mascarando o resultado ao inibir a floração de algas, o que não necessariamente indica o não potencial.

Por outro lado, O IET PT apontou a potencial eutrofização, com classe mesotrófica, com risco intermediário de eutrofização, ratificando que as concentrações de fósforo estão em sua maioria, acima do valor de referência da Resolução CONAMA n³ 357/2005. O regime hidrológico na bacia apresenta influência sobre a potencial eutrofização do rio, principalmente no período de transição da seca para o início das chuvas, entre outubro e novembro.

Assim, as concentrações de nutrientes disponíveis na coluna líquida superficial, conjugado a ocorrência de eventos climáticos extremos, poderá acarretar a eutrofização do rio Urupá. Para evitar possíveis riscos de eutrofização e/ou ainda atenuar a disponibilidade nutricional nos corpos hídricos é imprescindível a adoção de medidas adequadas de gestão das atividades econômicas da bacia.

Contudo, deve-se sistematizar e intensificar as formas de monitoramento e controle das atividades de uso e ocupação do solo na bacia do rio Urupá, e o seu ordenamento, de forma reduzir o aporte de nutrientes para o leito do rio Urupá, considerando o iminente risco de eutrofização e a difícil reversão de um quadro de desequilíbrio.

\section{REFERÊNCIAS}

ANA. Agência Nacional de Águas. Portal da qualidade das águas. Indicadores de qualidade. Índice de estado trófico (IET). ANA, 2019

ANA. Agência Nacional de Águas. Hidroweb: Sistemas de informações hidrológicas. ANA, 2019.

ALVES, I. C. C.; EL-ROBRINI, M.; SANTOS, M. L. S.; MONTEIRO, S. M.; BARBOSA, L. P. F.; GUIMARÃES, J. T. F.. Qualidade das águas superficiais e avaliação do estado trófico do Rio Arari (Ilha de Marajó, norte do Brasil). Acta Amazônica, v.42, n.1, p.115-124, 2012. DOI: http://doi.org/10.1590/s0044$\underline{59672012000100014}$

APHA; AWWA; WEF. American Public Health Association American Water Works Association; Water Environment Federation. Standard methods for the examination of water and wastewater. 19 ed. Washington: APHA, 1999.

BRIZZI, R. R.; PORTOCARRERO, H.; SOUZA, A. P.; COSTA, A. J.
S. T.; RANGEL, L. A.. Avaliação macro e microestrutural de solos sob diferentes usos a partir de análises físicas, microscopia eletrônica e espectroscopia por energia dispersiva. R. Ra'e Ga., Curitiba, v.46, p.25-40, 2019. DOI: http://doi.org/10.5380/raega

CETESB. Companhia Ambiental do Estado de São Paulo. Guia nacional de coleta e preservação de amostras: água, sedimento, comunidades aquáticas e efluentes líquidas. São Paulo: CETESB; Brasília: ANA, 2011.

CETESB. Companhia Ambiental do Estado de São Paulo. Norma técnica L5.306: Determinação de Clorofila a e Feofitina a: método espectrofotométrico. São Paulo: CETESB, 2014.

CONAMA. Conselho Nacional de Meio Ambiente. Resolução n. 357, de 25 de março de 2005. Dispõe sobre a classificação dos corpos de água e diretrizes ambientais para o seu enquadramento, bem como estabelece as condições e 
padrões de lançamento de efluentes. Ministério do Meio Ambiente. Brasília: CONAMA, 2005.

CYRINO, J. E. P.; BICUDO, A. J. A.; SADO, R. Y.; DAIRIKI, J. K.. A piscicultura e o ambiente: o uso de alimentos ambientalmente corretos em piscicultura. R. Bras. Zootec., v.39, p.68-87, 2010. DOI: http://dx.doi.org/10.1590/S1516$\underline{35982010001300009}$

DAVIDSON, E. A.; ARAÚJO, A. C.; ARTAXO, P.; BALCH, J. K.; BROWN, I. F. C.; BUSTAMANTE, M. M.; WOFSY, S. C.. The Amazon basin in transition. Nature, v.481, n.7381, p.321 328, 2012. DOI: http://doi.org/10.1038/nature10717

EMBRAPA. Empresa Brasileira de Pesquisa Agropecuária. Sistema brasileiro de classificação de solo. 5 ed. Brasília: EMBRAPA, 2018.

EMBRAPA. Empresa Brasileira de Pesquisa Agropecuária. Agência Embrapa de informação tecnológica. Arvore do conhecimento solos tropicais. Argissolos vermelho-amarelo. 2019.

ESPINOZA, J. C.; RONCHAIL, J.; MARENGO, J. A.; SEGURA, H. Contrasting North-South changes in Amazon wet-day and dry-day frequency and related atmospheric features (19812017). Climate Dynamics, v.52, p.5413-5430, 2018. DOI: http://doi.org/10.1007/s00382-018-4462-2

FARAGE, J. A. P.; MATOS, A. T. M.; SILVA. D. D.; BORGES, A. C.. Determinação do índice de estado trófico para fósforo em pontos do Rio Pomba. Revista de Engenharia na Agricultura, Viçosa, v.18, n.4, 2010. DOI: http://doi.org/10.13083/reveng.v18i4.98

FISCH, G.; MARENGO, J. A.; NOBRE, C. A.. Clima da Amazônia. Centro de Previsão de Tempo e Estudos Climáticos, 2019.

GOLTERMAN, H. L.; BAKELS, C. C.; JAKOBS-MÖGELIN, J.. Availability of mud phosphates for the growth of algae. SIL Proceedings, v.17, p.1, p.467-479. 1969. DOI: http://doi.org/10.1080/03680770.1968.11895874

IBGE. Instituto Brasileiro de Geografia e Estatística. Geociências. Rio de Janeiro: IBGE, 2003.

KANNA, J.; MEDVIGY, D.; FUEGLISTALER, S.; WALKO, R.. Regional dry-season climate changes due to three decades of Amazonian deforestation. Nature Climate Change, v.7, n.3, p.200-204, 2017. DOI:

http://doi.org/10.1038/nclimate3226

LAMPARELLI, M. C.. Grau de trofia em corpos d'água do estado de São Paulo: avaliação dos métodos de monitoramento. Tese (Doutorado em Ciência - ecossistemas terrestres e aquáticos) - Universidade de São Paulo, 2004.
MARANHO, L. A.; BOTELHO, R. G.; NOGUEIRA, L. A.; TORNISIELO, V. L.. Avaliação da qualidade da água do Ribeirão Samambaia (São Pedro, São Paulo, Brasil) através de parâmetros físicos e químicos, índice de estado trófico e teste de toxicidade com Daphnia magna. Engenharia Sanitária e Ambiental, v.22, n.1, p.195-201, 2017. DOI: http://doi.org/10.1590/s1413-41522017130372

MARRETO, R. N.; BAUMGARTEN, M. G. Z.; WALLNERKERSANACH, M.. Trophic quality of waters in the Patos Lagoon estuary: a comparison between its margins and the port channel located in Rio Grande, RS, Brazil. Acta Limnologica Brasiliensis, v.29, n.11, 2017. DOI: http://dx.doi.org/10.1590/S2179-975X10716

MEZZOMO, M. M.; GASPARINI, G. S.. Estudo da alteração antrópica (hemerobia) da bacia hidrográfica do rio Mourão/PR. Curitiba: R. Ra'e, v.36, p.280-301, 2016. DOI: http://dx.doi.org/10.5380/raega.v36i0.43437

MOURA, L. H. A.; BOAVENTURA, G. R.; PINELLI, M. P.. A qualidade de água como indicador de uso e ocupação do solo: bacia do Gama - Distrito Federal. Brasília: Química Nova, v.33, n.1, p.97-103, 2010. DOI: http://dx.doi.org/10.1590/S0100-40422010000100018

NOBRE, C. A.. Por trás da seca na Amazônia. Mudanças Climáticas. 42 ed. 2011.

OLIVEIRA, S. A.; BICUDO, C. E. M.. Variação sazonal das características limnológicas e Índice de Estado Trófico de dois reservatórios oligotróficos do sudeste do Brasil. Braz. J. Biol., 2017, v.77, n.2, p.323-331, 2016. DOI: http://dx.doi.org/10.1590/1519-6984.14015

POMATI, F.; MATTHEWS, B.; SEEHAUSEN, O.; IBELINGS, B. W.. Eutrophication and climate warming alter spatial (depth) co-occurrence patterns of lake phytoplankton assemblages. Hydrobiologia, v.787, n.1, p.375-385, 2016. DOI: http://doi.org/10.1007/s10750-016-2981-6

SCHNEIDER, R. M.; ANDRIETTI, G.; FREIRE, R.; AMARAL, A. G.; ALMEIDA, F. T.; BONGIOVANI, M. C.. Índices de qualidade da água e de estado trófico do rio Caiabi, MT. Ambiente e Agua: An Interdisciplinary Journal of Applied Science, v.11, n.1, 2016. DOI: http://doi.org/10.4136/ambi-agua.1769

SINHA, E.; MICHALAK, A. M.; BALAJI, V.. Eutrophication will increase during the 21st century as a result of precipitation changes. Science, v.357, n.6349, p.405-408, 2017. DOI: http://doi.org/10.1126/science.aan2409

STAGER, J. C.; WILTSE, B.; HUBENY, J. B.; YANKOWSKY, E.; NARDELLI, D.; PRIMACK, R.. Climate variability and cultural eutrophication at Walden Pond (Massachusetts, USA) during the last 1800 years. Plos One, v.13, n.4, 2018. DOI: http://doi.org/10.1371/journal.pone.0191755

A CBPC - Companhia Brasileira de Produção Científica (CNPJ: 11.221.422/0001-03) detém os direitos materiais desta publicação. Os direitos referem-se à publicação do trabalho em qualquer parte do mundo, incluindo os direitos às renocões, expansões e disseminoc̃os da contribuiç̃o, bem como outros direitos subsidiários. Todos os trabalhos publicados eletronicamente poderão 作 preservam os direitos autorais, mas não têm permissão para a publicação da contribuição em outro meio, impresso ou digital, em português ou em tradução. 